\title{
Perception of objective structured clinical examination and traditional practical examination in assessment of nursing students clinical competencies by nursing students in south west Nigeria
}

\author{
Mary Idowu Edward ${ }^{1}$, Funmilayo Okanlawon ${ }^{2}$ \\ ${ }^{1}$ Mary Idowu Edward, Ondo State School of Nursing, ${ }^{2}$ Funmilayo Okanlawon, Department of Nursing, University of \\ Ibadan, Nigeria
}

Address for correspondence: Mary Idowu Edward, Email: moj750@gmail.com

\begin{abstract}
Background: Clinical examination is a crucial part of nursing training programmes for assessing nursing student competencies which ultimately lead to the delivery of quality nursing care. Two methods of clinical assessment have been identified [Traditional Practical Examination (TPE) and Objective Structured Clinical Examination(OSCE)] in nursing and allied professions globally. Nursing and Midwifery Council of Nigeria (N\&MCN) had always used TPE for all clinical examinations in nursing but adopted OSCE two decades ago for only midwifery examination while the examination in general nursing still remains TPE. There is dearth of literature on the perception of these two methods in Nigeria hence this study. This will help to determine best preferred method for clinical assessment among nursing students in Nigeria. Methods: The study utilised one-group quasi experimental design. Two Hospital-based and two University-based nursing schools randomly selected in South-west Nigeria participated in the study. Purposive sampling technique was used to select 187 nursing students out of which 157 participated in the study. T-test, ANOVA and chisquare were used to analyze the data at 0.05level of significance. Results: Significant difference existed between the mean scores of the two practical examinations: TPE 59.31 \pm 2.92 , OSCE $64.59 \pm 5.15, \mathrm{t}=3.29, \mathrm{p}=0.002$. OSCE was perceived to be more objective compared to TPE, $p=0.000$, consume less time $p=0.010$, assessed wider range of learned materials, $\mathrm{p}=0.000$, less destabilizing during practical session, $\mathrm{p}=0.001$, less stressful $\mathrm{p}=0.002$. Perception on which method demands more preparation showed no significant difference between OSCE and TPE, $\mathrm{p}=0.097$. Lastly, 56.8\% of participants preferred OSCE to TPE, $\mathrm{p}=0.001$. Conclusion: OSCE is perceived to be a better method than TPE. It is recommended that OSCE should be adopted as method of practical examination for nursing training programmes in Nigeria.
\end{abstract}

Keywords: Perception, Objective Structured Clinical Examination (OSCE), Traditional Practical Examination (TPE), Objective

\section{Introduction}

Evaluation of nursing competency is critical to assuring patient safety and maintaining high professional standards in the practice of nursing [9]. Competencies refer to skills or knowledge that leads to superior performance. These are formed through an individual/organization's knowledge, skills and abilities and provide a framework for distinguishing between poor performances through to exceptional performance. A competency is a combination of skills, abilities, and

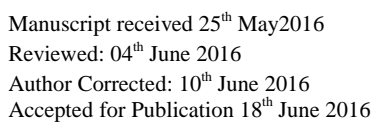

knowledge needed to perform a specific task in a given context [8]. competence should be concerned with the ability to master specific clinical skills and possess necessary personal characteristics to function effectively as a nurse including the capacity for reflection [3].

Assessment of competence of practising nurses has been identified as crucially important in maintaining professional standards identifying areas for professional development and educational needs and ensuring that nurse competencies are put to the best possible use in 
patient care. In view of the holistic definition of competence, there is general agreement that competence assessment in nursing cannot solely be based on demonstration of theoretical content knowledge or technical skills but should also involve some inference about a candidate's attitudes and practice. OSCE has been adopted as an assessment tool for evaluating the clinical performances of both undergraduate and graduate medical students. The measurement of nursing students' clinical skills performance continues to pose a challenge for nurse educators. Evaluations of students' performance in institutions of learning have been carried out for ages. Methods of evaluation have become more sophisticated, particularly with the development and implementation of innovative educational curricula [10].

In developing countries, there is shortage of assessment experts to guide the formulation of valid and reliable assessment method. There are no universally agreed techniques and methodologies for assessment of variety of domains learned in nursing education programme [10]. Oral practical examinations guide used presently has been criticised as having some deficiencies in terms of reliability. Marks awarded to candidates by different examiners indicate low reliability between the ratings of student for different procedures. Agreement between examiners is often poor and there is variation in questions asked from candidate to candidate. Objective Structured Clinical Examination (OSCE) is widely used in Medicine as a major instrument of evaluation for medical students and this is evident in OSCE abounding more in medical literature. OSCE may be a powerful tool in the evaluation of clinical competence in nursing and that it may also be an effective facilitator for learning to perform clinical skills in nursing [12]. Objective Structured Clinical Assessment (OSCA) is suggested to be an effective way of assessing student comprehensive nursing performance [2].

Although the Objective Structured Clinical/Practical Examination (OSCE) appears to be promising method for evaluating competence in the performance of clinical skills, there are few studies in the nursing literature examining the use of the OSCE as a method for evaluating the performance of clinical skills by nurses. In a study conducted by [1] on Objective structured clinical examination vs traditional clinical examination: An evaluation of students' perception and preference in a Nigerian medical school, One hundred and thirty-one respondents (84\%) felt TCE is more difficult and $20(12.8 \%)$ felt OSCE was more difficult.
One hundred and forty-two (91\%) felt OSCE was easier to pass, $8(5.1 \%)$ felt TCE was easier to pass and 6 $(3.8 \%)$ were undecided. Majority of the students preferred OSCE for assessment. In relation to validity and reliability of OSCE, $124(79.5 \%)$ of all the students felt it provides a true measure of essential clinical skills, $130(83.3 \%)$ felt its scores are standardised and 143 $(91.7 \%)$ felt it is a practical. Overall, there were no significant differences in preference and perceptions. Students preferred OSCE as method of assessing clinical competence and considered it a more valid and reliable method of examination. The students' perceptions of OSCE compared to CPE, 73\% responded that OSCE could partially or completely replace CPE. OSCE was judged as an objective and unbiased test as compared to CPE, by $66.4 \%$ of the students [15].

According to [10] in a study conducted on Assessment of III MBBS Students using OSCE in Community Medicine: Teachers' and students' Perceptions, students disagreed that OSCE is a stressful examination in contrast with the opinion of the teachers, students found difficulty in management of time at some stations so they demanded more time to be given for these stations. Most of the students and teachers agreed that examiner bias may be eliminated by following this type of assessment. They also agreed that it is easier to pass OSCE as compared to traditional practical examination. Both students and teachers accepted that this type of examination is better than the traditional practical examination.

In a study conducted on Objective structured practical examination (OSCE) as a tool for the formative assessment of practical skills of undergraduate students in pharmacology by [15] the results suggest that OSCE and CPE are in agreement as seen in the Bland Altman plot of the two methods, which shows that $96 \%$ of the values lie within the limits of the mean of $\pm 1.96 \mathrm{SD}$. Thus OSCE can replace CPE in the formative assessment. These findings differ from the previous studies, which show a significant difference between the CPE and OSCE scores. The students' perceptions with regard to the difficulty level only about few numbers of the students perceived OSCE as more difficult than CPE, suggesting that it would be acceptable to a majority of students in case it replaces CPE. The time for conducting OSCE was also less, as perceived by a majority $(95 \%)$ of the students. For the faculty also, the time for conducting OSCE was reduced compared to CPE. About $63 \%$ of the students felt that OSCE provided optimum coverage of the course. It 
was also shown that the students responded positively $(66.4 \%)$ to the OSCE format and it was perceived to be more fair and objective than the conventional examination. The strength of the study was that all the students were exposed to both the types of examinations, CPE and OSCE, and were in position to give their opinion. Large group of students were assessed with OSCE in a shorter time than with CPE.

Statement of the Problem-The purpose of practical examination is to ensure that students are objectively assessed without sentiment or bias with the understanding that they can rise up to challenges of clinical practice. Assessment of clinical competence of nursing students has constituted a problem to nurse educators. In Traditional practical examination, questions are not structured along a clearly defined pattern. Objective Structured Clinical Examination (OSCE) has been successfully used for students in other disciplines such as midwifery, community health nursing, medicine, pharmacy and physiotherapy. It addresses the above deficiencies and lapses in the traditional methods of clinical examination. According to [4] implementation of OSCE is time-consuming, and requires huge effort and extensive resources. It also requires a large number of qualified personnel to observe and evaluate students during OSCE. The above mentioned problems/deficiencies have stirred up the interest of the researcher to look critically into and find out the students' perception on the two methods of assessing nursing students during practical examination.

\section{Objectives of the Study}

1. To compare the nursing students' performances scores in TPE and OSCE in the selected Schools and Departments of Nursing in the study settings.

2. To assess the perception and preference of nursing students towards the use of OSCE and TPE

\section{Research Questions}

In order to achieve the objectives of this study the following questions were asked:

1. What is the difference between nursing students' performance scores obtained from OSCE and TPE?

2. What is the perception and preference of nursing students towards the use of OSCE and TPE methods for assessing them during practical examination?

Significance of the Study-The measurement of clinical skills performance has been posing challenges for nurse educators.

Results of the study have:
- Provided comparative data between OSCE and the TPE methods of assessing nursing students' clinical competency. OSCE is thereby established as the better of the two approaches in the area of objectivity, time consumption and coverage large learned materials.

- Identified that OSCE is the most preferred methods of assessing the nursing students.

- Contributed to the available literature on OSCE as an approach for evaluating clinical competency in nursing programmes in Nigeria.

- Confirmed that public will enjoy better services from nurses who would have been assessed and certified through the use of more effective practical method.

Hypothesis: There will be no significant difference in the perception and preference of nursing students towards OSCE and TPE.

\section{Materials and Methods}

The study utilised quasi design to assess perception of objective structured clinical examination and traditional practical examination in assessment of nursing students' clinical competencies by nursing students in south west Nigeria.

Population of the study- The population for the study were the students of selected hospital based schools of nursing and university based nursing students.

\section{The instruments for data collection}

- Objective Structured Clinical Examination Instruments (OSCEI). This was developed to score students during OSCE which is the experimental practical examination. The newly designed OSCE instruments were administered by educators/assessors on the nursing students of four (4) selected nursing programmes during practical examination to assess the students' clinical skills.

- Traditional Practical Examination Instrument (TPEI). This is the accepted assessment format by Nursing and Midwifery Council of Nigeria (NMCN) used to assess nursing students during practical examination at all levels. It was adopted in this research during the TPE which was the Control Examination to assess nursing students.

- Students Demographic and Perception Questionnaire (SDPQ). This is a structured questionnaire which was administered to students following the examination to elicit their perception on the effectiveness of the use of OSCE in assessment of their clinical skills in comparison with the TPE. 
Validity of the instrument-The instrument was given to expert in the field and all necessary corrections based on content and face validity of the instrument were corrected.

Reliability of the instrument-The reliability of the instrument was determined by pilot testing. This was done in Ekiti State University Teaching Hospital, School of Nursing. The reliability coefficients of the instrument were determined using Cronbach's Alpha statistical method. The values obtained are as follows: Students Demographic and Perception Instrument (SDPI) .840
Sample and sampling techniques- Two Hospitalbased and two University-based nursing schools were randomly selected in South-west Nigeria. The four schools participated in OSCE. 157 participants were purposively selected to participate in the study.

Method of data collection- Data were obtained using self developed and validated Students' Demographic and Perception Questionnaire (SDPQ).

Method of data analysis-Data were analysed using descriptive statistics for demographic variables and students' $\mathrm{T}$ test, ANOVA with Chi-square test at 0.05level of significance to analyze the hypothesis.

\section{Result}

Socio-Demographic Characteristics of Nursing students in the Study- The population distribution of nursing students in the study as presented in Table 1 shows that 157 students took part in the two practical examinations, that is, OSCE and TPE. Table 4.2 showed that 148 out of 157 respondents completed and returned the questionnaires thus given $94.2 \%$ return rate. One hundred and forty-one respondents $(95.1 \%)$ were within the age range of 18 to 25 years mean age was 21.5 years \pm 3.8 years. Majority $110(74.3 \%)$ respondents were female and more than half $87(58.7 \%)$ were hospital based second year nursing students with the rest 61(41.3\%) being university-based generic nursing students. Majority of respondents $123(83.1 \%$ ) were of Yoruba ethnic group spread across the Yoruba speaking States of south-west Nigeria. The rest were from Edo 9 (6.1\%), Imo 6(4.1\%), Kogi 6(4.1\%) and Anambra 4 (2.7\%).

Table-1: Socio-Demographic Characteristics of nursing students

\begin{tabular}{|l|l|l|l|}
\hline $\begin{array}{l}\text { Socio-demographic } \\
\text { characteristics }\end{array}$ & Variables & $\begin{array}{l}\text { Frequency } \\
\text { N=148 }\end{array}$ & \% \\
\hline Sex & Male & 38 & 25.7 \\
& Female & 110 & 74.3 \\
\hline Age on admission & $<20$ & 66 & 44.5 \\
& $20-25$ & 75 & 50.6 \\
& 25 and above & 7 & 4.7 \\
\hline Level of study & Basic 2 Year & 87 & 58.7 \\
& Generic 300 level & 61 & 41.3 \\
\hline State of origin & Ondo & 32 & 21.6 \\
& Oyo & 25 & 16.9 \\
& Osun & 26 & 17.6 \\
& Ogun & 10 & 6.8 \\
& Lagos & 7 & 4.7 \\
& Ekiti & 23 & 15.5 \\
& Edo & 9 & 6.1 \\
& Imo & 6 & 4.1 \\
& Kogi & 6 & 4.1 \\
& Anambra & 4 & 2.7 \\
\hline Ethnicity & Yoruba & 127 & 85.8 \\
& Igbo & 10 & 6.8 \\
& Benin & 11 & 7.4 \\
\hline Religion & Christianity & 67.6 \\
& Islam & 100 & 32.4 \\
\hline
\end{tabular}


Objective-1: To compare the nursing students' performance scores in Traditional and Objective Structured Clinical Examinations in the selected Schools and Departments of Nursing in the study setting.

Hypothesis-1: There will be no significant difference in the scores obtained in Traditional Practical Examination (TPE) and Objective Structured Clinical Examination (OSCE) in the selected Schools and Departments of Nursing in the study setting.

In order to test this hypothesis a paired sample t-test was conducted to compare the performance in TPE and OSCE at $\mathrm{P}=0.05$ confidential interval. There was a significant difference in the scores in TPE and OSCE. TPE mean 59.31 \pm 2.92 , OSCE mean $64.59 \pm 5.15, \mathrm{t}=3.29, \mathrm{P}=0.002$. The null hypothesis is therefore rejected. The results suggested that there was a significant difference in the scores of TPE in the selected Schools and Departments of Nursing, and OSCE in the selected Schools and Departments of Nursing in the study setting.

Table-2: Comparison of nursing students' scores in TPE and OSCE

\begin{tabular}{|c|c|c|c|c|c|c|c|c|c|}
\hline \multicolumn{10}{|c|}{ Paired Samples Test } \\
\hline & & \multicolumn{5}{|c|}{ Paired Differences } & \multirow[t]{3}{*}{$\mathrm{T}$} & \multirow[t]{3}{*}{ Df } & \multirow{3}{*}{$\begin{array}{l}\text { Sig. } \\
\text { (2-tailed) }\end{array}$} \\
\hline & & \multirow[t]{2}{*}{ Mean } & \multirow[t]{2}{*}{$\begin{array}{l}\text { Std. } \\
\text { Deviation }\end{array}$} & \multirow[t]{2}{*}{$\begin{array}{l}\text { Std. } \\
\text { Error } \\
\text { Mean }\end{array}$} & \multicolumn{2}{|c|}{$\begin{array}{l}95 \% \text { Confidence } \\
\text { Interval of the } \\
\text { Difference }\end{array}$} & & & \\
\hline & & & & & Lower & Upper & & & \\
\hline \multirow[t]{2}{*}{ Pair 1} & OSCE & 64.59 & 5.15 & 0.72 & 3.72 & 5.56 & 3.29 & 157 & .002 \\
\hline & TPE. & 59.31 & 2.92 & & & & & & \\
\hline
\end{tabular}

Perception of Nursing students about OSCE and TPE- The table 3 shows ANOVA analysis of difference in respondents' perception on the two methods of examinations based on six parameters. On time consumption, result shows a significant difference in the respondents' perception of OSCE and TPE with OSCE perceived to consume less time than TPE, $F=4.758, p=0.010$. On the objectivity, respondents were of the opinion that OSCE was significantly different from TPE with OSCE viewed to be more objective, $\mathrm{F}=13.273, \mathrm{p}=0.000$. On the ability of the methods to assess wide range of learning materials, results shows difference in the respondents opinion which is statistically significant OSCE perceived as assessing wider range of learned materials than TPE, $F=8.244, p=0.000$.

However, the perception on demand more preparation shows that there is no significant difference on the respondents opinion about OSCE and TPE, $\mathrm{F}=1.641, \mathrm{p}=0.097$. On which of the methods is less destabilizing during practical session, the result shows significant difference between OSCE and TPE, F=7.835, p = 0.001. OSCE was perceived to be less destabilising during practical examination. Lastly, on which method is less stressful, the respondents' opinion show that OSCE is significantly different from TPE, $\mathrm{F}=6.378, \mathrm{p}=0.002$. OSCE was perceived to be less stressful. Testing for the significance of the respondents difference in perception about the two examinations with the 8 parameters combined, the result shows that there is significant difference in the perception of students nurses about the two examinations $\mathrm{F}=$ $10.921, \mathrm{p}=.039$. OSCE was perceived to be better than TPE.

Comparison of Nursing students' Preference for OSCE and TPE- The nursing students' preference for OSCE and TPE was computed using percentage and chi square test. Table 3 shows the distribution of preference for the two practical examinations. The preferences for OSCE and TPE among University-based (generic) and basic nursing students are: Generic [OSCE 46(79.3\%), TPE 12(20.6\%)] and Basic [OSCE 38(42.2\%), TPE 52(57.7\%)] respectively. The preference for OSCE is more pronounced among generic students than basic nursing students. Generally, 56.8\% of nursing students prefer OSCE while $43.2 \%$ prefer TPE.At $95 \%$ confidence interval, there was statistically significant difference in preference. Numerically, $56.8 \%$ of all the students preferred OSCE compared with $43.2 \%$ TPE. Chi square value observed $38.240, \mathrm{df}=4, \mathrm{P}=0.001$ (table 5).

The null hypothesis is therefore rejected. 
Table-3: Comparison of Perception of nursing students about OSCE and TPE

\begin{tabular}{|c|c|c|c|c|c|c|}
\hline & & $\begin{array}{l}\text { Sum of } \\
\text { Squares }\end{array}$ & Df & $\begin{array}{l}\text { Mean } \\
\text { Square }\end{array}$ & $\mathbf{F}$ & Sig. \\
\hline LESS TIME & Between Groups & 5.466 & 2 & 2.733 & 4.758 & .010 \\
\hline CONSUMTION & Within Groups & 82.711 & 144 & .574 & & \\
\hline & Total & 88.177 & 146 & & & \\
\hline MORE OBJECTIVE & Between Groups & 10.650 & 2 & 5.325 & 13.273 & .000 \\
\hline & Within Groups & 57.772 & 144 & .401 & & \\
\hline & Total & 68.422 & 146 & & & \\
\hline ASSESS A WIDE RANGE & Between Groups & 10.288 & 2 & 5.144 & 8.244 & .000 \\
\hline OF LEARNED & Within Groups & 89.848 & 144 & .624 & & \\
\hline MATERIALS & Total & 100.136 & 146 & & & \\
\hline DEMANDS MORE & Between Groups & 1.537 & 2 & .769 & 1.641 & .097 \\
\hline PREPARATION & Within Groups & 67.456 & 144 & .468 & & \\
\hline & Total & 68.993 & 146 & & & \\
\hline LESS DESTABILISING & Between Groups & 6.958 & 2 & 3.479 & 7.835 & .001 \\
\hline DURING PRACTICAL & Within Groups & 63.940 & 144 & .444 & & \\
\hline EXAMS & Total & 70.898 & 146 & & & \\
\hline LESS STRESSFUL & Between Groups & 6.501 & 2 & 3.251 & 6.378 & .002 \\
\hline & Within Groups & 73.390 & 144 & .510 & & \\
\hline & Total & 79.891 & 146 & & & \\
\hline STUDENTS' GENERAL & Between Groups & 1579.667 & 44 & 35.902 & 10.921 & .039 \\
\hline & Within Groups & 4404.043 & 113 & 38.974 & & \\
\hline & Total & 5983.710 & 157 & & & \\
\hline
\end{tabular}

Table-4: Comparison of nursing students' preference using training institutions

\begin{tabular}{|l|l|l|l|}
\hline Training Institutions * Which one do you prefer? \\
\hline Training Institutions & OSCE & TPE & Total \\
\hline University-based training & $46(79.3 \%)$ & $12(20.6 \%)$ & 58 \\
\hline Hospital- based training & $38(42.2 \%)$ & $52(57.7 \%)$ & 90 \\
\hline Total & $84(56.8 \%)$ & $64(43.2 \%)$ & 148 \\
\hline
\end{tabular}

Table-5: Nursing students' Preference for the Two Methods of Practical Examination

\begin{tabular}{|l|l|l|l|}
\hline Chi-Square Tests & Value & Df & Asymp. Sig. (2-sided) \\
\hline Pearson Chi-Square & $38.240^{\mathrm{a}}$ & 4 & .001 \\
\hline Likelihood Ratio & 16.553 & 4 & .002 \\
\hline No of Valid Cases & 148 & & \\
\hline
\end{tabular}

Reasons for Preference of one Examination to the other by Nursing students- The reasons why nursing students prefer TPE to OSCE is as shown in table 6. Some of the reasons are that it allows communication with patients, gives room for correction, helps to understand better, and promotes skills and knowledge with exposure to real life situation having the highest, 16 students $(25 \%)$. The reasons why nursing students prefer OSCE to TPE is also shown in table 5. The table shows some of the reasons why nursing students prefer OSCE which ranges from: Saves time and easier $(8.3 \%)$, scores correlate with knowledge $(30.9 \%)$, wide coverage of skills $(27.3 \%)$ and more realistic $(22.6 \%)$. 
Table-6: Reason for Preferring TPE and OSCE by Students

\begin{tabular}{|l|l|l|}
\hline Reason for Preferring TPE & Frequency & Percentage \\
\hline Communicate with patients & 15 & 23.4 \\
\hline Exposure to real life situation & 16 & 25 \\
\hline Gives room for correction & 13 & 20.3 \\
\hline Helps to understand better & 8 & 12.5 \\
\hline Promotes skills and knowledge & 4 & 6.25 \\
\hline Helps to think critically & 8 & 12.5 \\
\hline Total & $\mathbf{6 4}$ & $\mathbf{1 0 0}$ \\
\hline Reason for preferring OSCE & & \\
\hline Saves time and easier & 7 & 8.3 \\
\hline Scores correlate with knowledge & 26 & 30.9 \\
\hline Wide coverage of skills & 23 & 27.3 \\
\hline More realistic & 19 & 22.6 \\
\hline Total & $\mathbf{8 4}$ & $\mathbf{1 0 0}$ \\
\hline
\end{tabular}

\section{Discussions of findings}

Socio-demographic characteristics of students nurses under study-A total number of 157 students participated in the study. They took part in the two practical examinations, that is, OSCE and TPE. Only 148 out of 157 respondents completed and returned the questionnaires thus giving $94.2 \%$ return rate. The respondents' characteristics of age range and mean age of 21.5+3.8 years is consistent with Nursing and Midwifery Council of Nigeria age limit for would-be nursing students at any level of entry into the training program which stipulates that the nursing students must not be less than 17 years by the time of their indexing, usually six months after admission. The gross gender imbalance of $74.3 \%$ female and $25.7 \%$ male supports the general observation and believe that describe nursing as a predominantly female profession in Nigeria. All the respondents are either in their second year for basic students or 300level for generic students meaning that the respondents are familiar with the use of TPE as a form of practical examination but had their first major experience with the OSCE in this study. It was also discovered that the students came from various States of the Federation and of various ethnic groups with majority being Yoruba. This may be because the study was carried out in the south-western part of Nigeria which is predominantly a Yoruba speaking area.

Comparison of Performance Scores of Nursing Students Obtained from OSCE (Intervention Practical Examination) and TPE (Control Practical Examination)- The results in the four schools revealed a higher mean score in OSCE than TPE. This could be a reflection of the highly structured nature of OSCE and its scoring method which was designed to erase any form of bias. It could also be a reflection of the fact that the students prepared very well for the OSCE being a new method of practical examination. This result is contrary to the findings of a similar study by [11] where it was reported that the average scores obtained by the students in the two methods of practical examinations were nearly equal, that is, 61.2 in OSCE and 61.5 in CPE. Result is also contrary to the findings of [15] who reported that OSCE and CPE are in agreement because analysis of scores obtained from both practical examination shows that $96 \%$ of the values lie within the limits of the mean of \pm 1.96 SD. [5] discovered in their study that there was a highly statistically significant difference between the mean of Traditional Clinical Examination (TCE) score $(16.08 \pm 2.1)$ and the mean of and Objective Structured Clinical Examination (OSCE) score $(14.45 \pm 2.5)$.

However, this finding is in support of [13] and [6] who reported a higher mean score in OSCE when compared to TPE with a highly statistically significant differences.

Perception of students about OSCE and TPE- The students' perception about OSCE and TPE is discussed using six parameters: time consumption, objectivity, ability to assess wide range of learned materials, preparation for the examination, destabilisation and stress level during the practical examination session. The results are as shown in tables 3 . 
Perception about time consumption- Findings revealed that students perceived that OSCE is less time consuming in implementation than TPE. The opinion of the student respondents may be hinged on the fact that the time taken to get all students examined using OSCE was less than that for TPE. The findings of [15] who reported in their study that the time for conducting OSCE was less compared to CPE, (as perceived by majority of the students and faculty members) is directly in support of the students view. [4] reported on the contrary that the implementation of OSCE is more time consuming. The researcher however is of the opinion that OSCE consumes less time in terms of hours and days taken to conduct the examination. For instance, in OSCE it takes a day to examine every student while TPE takes two or three days to examine the same number of students.

Perception about objectivity-Findings about objectivity of the two methods of examinations revealed that majority of the students perceived that OSCE is more objective than TPE. This could be as result of the fact that in OSCE, all the students performed the same procedures during the practical examination and are scored according to the checklist provided which was designed to eliminate bias, whereas TPE is subjective because the procedures given to the students and the scoring are most times at the discretion of the examiners. This is congruent with the feedback from nursing students which showed that OSCE is an objective tool for evaluating clinical skills and its format was perceived to be more fair and objective than the conventional examination in pharmacology. The feedback further view OSCE scores as a true measure for essential clinical skills being evaluated, standardized, and not affected by students' personality or social relation $[5,15]$.

Perception about assessing wide range of learned material- Majority of the respondents students were of the opinion that OSCE was capable of assessing wider range of learned material than TPE. This may be a direct consequence of the fact that in OSCE students perform more than three procedures within a given hour whereas in TPE a student may not perform more than two procedures within the same time. This result supports the finding of [15] in a study where it was reported that majority of the students respondents felt that OSCE provided optimum coverage of the course. This finding is further supported by [7] who reported that students may over linger on one procedure in an attempt to avoid being given other procedures during the course of the conventional practical examination. In OSCE each procedure to be performed is timed this prevent student from over lingering on one procedure as obtained in TPE. [17] stated in support that instructions in OSCE are carefully written to ensure that the candidate is given a very specific task to complete within specified time. The OSCE is carefully structured to include parts from all elements of the curriculum as well as a wide range of skills.

Perception about preparation for the examinationThe study revealed that majority of the student respondents perceived OSCE as demanding less preparation than TPE. This finding on student perception is contrary to [17] which stated that preparing for OSCEs is very different from preparing for an examination on theory. It is essential to learn correct clinical method and then practice repeatedly until one perfects the method whilst simultaneously developing an understanding of the underlying theory behind the methods used. In doing this a candidate is able to get a feel of working to time and working under pressure. The researcher is also of the opinion that OSCE may demand more preparation for students as they will have to read in-between lines, role play some of the procedures to ensure that they are able to keep to time as all the procedures are timed.

Perception about destabilising during practical session- Regarding the stability of students during practical examination, results show that students perceived OSCE to be less destabilising during practical session than TPE. This may be because there is less interference between the students and the examiners during OSCE as the examiners only observe what students are doing and are not obliged to correct any noticeable mistake made by the students. In TPE practical session however, examiners in some instances are forced to correct the students' mistakes to avoid possible harm to the patients which may lead to psychological destabilisation of the students. The examiner too may experience anxiety for the fact that the patient safety may be compromised. In OSCE, simulated patients were used instead of live patients hence no fear of harming the patient is entertained either by students or examiners giving the students and educators a measure of composure. This finding is congruent with that of [7] who reported that there is inverse relationship between anxiety and performance of procedure in practical examinations. This could be interpreted to mean that anxiety brings about 
destabilisation which invariably has negative impact on performance.

\section{Perception about Stress Level during the} Examination- The study revealed a contrary perception of the students of the two examinations as regard the stress level. Students perceived OSCE to be less stressful than TPE. The students reported that they experience more stress preparing for TPE than when preparing for OSCE. This line of thinking by the student respondents may be because the students is directly involved in the preparation of their wards of practical examination in readiness for TPE. Findings of a study by [14] revealed that students perceived OSCE to be fairer and less stressful than traditional clinical examinations. [10] reported students' disagreement that OSCE is a stressful examination. These findings are contrary to that of [4] who reported that OSCE was perceived as a stressful experience. The researcher is however of the opinion that from the experience gathered during this study that OSCE is a bit more stressful either for the students TPE on all considerations.

\section{Implications of Results to Nursing Education-} Results from this study revealed that OSCE is more effective in assessing nursing students' clinical competency in nursing training programmes. Nursing students performed significantly better in OSCE than TPE, the implication of this discovery is that Nursing and Midwifery Council of Nigeria and other relevant stakeholders in nursing education should critically review the continuous use of TPE in Nursing training programmes with the aim of either replacing it outright with OSCE or remodelling it to correct the notable faults to reflect current realities in Nursing training and nursing education.

OSCE is more effective in testing student clinical competencies than TPE. What this implies is that OSCE can successfully replace TPE without the fear of losing credibility, quality or standard of practical examination.

Findings on the perception and preference for the two methods of practical examination show that students significantly preferred OSCE to TPE indicating that if OSCE is introduced into nursing as practical examination, the move will be positively embraced by students and nursing can successfully join other health profession such as midwifery, medicine, pharmacy and physiotherapy that are already implementing OSCE as the mode of practical examination in their training programmes.

Recommendations- Objective structured practical examination is a new development in the assessment of clinical competency of nursing students. On the strength of the findings of this research, the followings are recommended:

- The Nursing and Midwifery Council of Nigeria, that is, the body that regulates nursing education and the nurse educator, who prepares students for professional practice, should adopt the OSCE for the general nursing practical examination. This will help in eliminating bias and subjectivity that is inherent in the current method of practical examination. The fact still subsist that the essence of nursing education is to produce nurses that are clinically competent to render quality care to patients and to achieve this lofty idea and goal, OSCE should be fully adopted at all levels of nursing training.

- Schools and departments of nursing demonstration laboratories in Nigeria should be equipped with necessary manikins and body parts so as to enhance the valuable learning and assessment opportunities inherent in the clinical education component of our nursing programs.

- There is a need to create competency-based curriculum for nursing education with OSCE process being inculcated into general/generic nursing program curriculums in Nigeria.

\section{Conclusion}

Summary and Conclusion- This study was carried out to assess the perception of objective structured practical examination and traditional practical examination in assessing clinical competency of nursing students in selected nursing training institutions in south-west Nigeria. The study utilised quasi experimental design. TPE which is control and OSCE which is experimental are both forms of practical examination for assessing nursing students in this study. Four schools (two departments of Nursing and two schools of Nursing) were randomly selected for the study. These schools were used as both control and experimental groups. A total of ten (10) OSCE stations were used viz: three (3) observed stations, two (2) skill description stations and five (5) question stations. A total of one hundred and fifty seven students participated in the study.

Evidence from findings revealed that students performed significantly better in OSCE than TPE in the final analysis. The study further revealed that majority 
of the students' were of the opinion that OSCE assess wide range of learned materials, consumes less time, was less destabilising during practical session, was less stressful and has a higher number of students preferring it over TPE. The respondents believed that OSCE scores are more objective than TPE scores. Information and experiences from other health programmes that practice OSCE such as midwifery, medicine, pharmacy and physiotherapy suggest that OSCE is more capable and its less biased in assessing and scoring students during practical session. It is therefore concluded from the results of this study that OSCE method of practical examination is more effective in assessing nursing students' clinical competency and perceived to be better than TPE.

Funding: Nil, Conflict of interest: None initiated, Permission from IRB: Yes

\section{References}

1. Ameh N, Abdul MA, Adesiyun GA, Avidime S. Objective structured clinical examination vs traditional clinical examination: An evaluation of students' perception and preference in a Nigerian medical school. Niger Med J. 2014 Jul;55(4):310-3. doi: 10.4103/03001652.137191 .

2. Bujack, L., McMillan. M., Dwyer, J., and Hazeton, M.2004. Assessing comprehensive nursing performance: the Objective Structural Clinical Assessment (OSCA) Part 1 - Development of the assessment strategy retrieved June, 12 2012 from http:www.sciencedirect.com Retrieved 12th Jan 2012, from http://www.nmcuk. org.

3. Cassidy S. Subjectivity and the valid assessment of pre-registration student nurse clinical learning outcomes: implications for mentors. Nurse Educ Today. 2009 Jan;29(1):33-9. doi: 10.1016/j.nedt.2008.06.006. Epub 2008 Aug 15.

4. El-Nemer, A and Kandeel, N. 2009. Using OSCE as an Assessment Tool for Clinical Skills: Nursing Students' Feedback Australian Journal of Basic and Applied Sciences, 3(3): 2465-2472.

5. Eman, A.M.M., Elsayeda, I.A., Amel, A.E., Mona, A.E. and Mastoura, K.F. 2014. The Impact of the Objective Structured Clinical Examination Approach for Clinical Evaluation Skills on the Student's Performance in Nursing College World Journal of Medical Sciences 2014;11 (4): 609-613.
6. Hassan, s., Malik,S., Hamad,A., Khab, H. and Bilal, M. 2009. Conventional/Traditional

Practical Examination(CPE/TDPE)Versus Objective Structured Practica Evaluation(OSCE)/Semi Objective Structured Practical Evaluation(SOSCE). Pak. J.Physiol 2009:5(1). Retrieved March 30, 2013 from httlp:/www.pps,org.pk

7. Jafarzadeh, A. 2009. Designing the OSCE method for evaluation of practical immunology course of medical students: in comparison to written-MCQ and Oral examination. Retrieved March 30, 2013 from www.scopemed.org.

8. Jones, E.A., Voorhees, R.A and Paulson., K. 2002. Defining and Assessing Learning: Exploring Competency-Based Initiatives, National Center for Education Statistics Office of Educational Research and Improvement U.S. Department of Education.

9. Linda, Schoene \& Kanusky, 2007. The Role of the Clinical Educator in Evaluating. Part of the Education Commons, and the Nursing Administration Commons. Retrieved $\quad 30^{\text {th }} \quad$ September $\quad$ 2013from http://digitalcommons.library.tmc.edu/uthshis_atldayabs

10. Ngatia P.M. and Mutema, A.M. 2006. Principles and practices of problem based Learning. AMREF and MOI University Press, Kenya.

11. Om Lata, B, Bharti, B., Bharati, M., and Sabyasachi, S126. 2014. Objective Structured Practical Examination and Conventional Practical Examination: a Comparison of Scores Journal of Medical Educators.

12. Ross M, Carroll G, Knight J, Chamberlain M, Fothergill-Bourbonnais F, Linton J. Using the OSCE to measure clinical skills performance in nursing. $\mathrm{J} \mathrm{Adv}$ Nurs. 1988 Jan;13(1):45-56.

13. Shadia A.E. and Nagwa A.A.H. 2013. Objective Structured Clinical Evaluation (OSCE) versus Traditional Clinical Students Achievement at Maternity Nursing: A Comparative Approach. IOSR Journal of Dental and Medical Sciences (IOSR-JDMS) e-ISSN: 2279-0853, p-ISSN: 2279-0861. Volume 4, Issue 3 (Jan.-Feb. 2013), PP 63-68 www.iosrjournals.org retrieval date February $28^{\text {th }}, 2016$ 
14. Smith LJ, Price DA, Houston IB. Objective structured clinical examination compared with other forms of student assessment. Arch Dis Child. 1984 Dec;59(12):1173-6.

15. Supriya D. M, Kartik N. S and Varsha J. P, 2013. Objective structured practical examination as a tool for the formative assessment of practical skills of undergraduate students in pharmacology $\mathrm{J}$ Educ Health Promot. 2: 53 Medknow Publications. Retrieved 28 ${ }^{\text {th }}$

Promot. $2:$

\section{How to cite this article?}

Mary Idowu Edward, Funmilayo Okanlawon. Perception of objective structured clinical examination and traditional practical examination in assessment of nursing students clinical competencies by nursing students in south west Nigeria . Int J Med Res Rev 2016;4(8):1340-1350.doi:10.17511/ijmrr.2016.i08.11.
16. Wadde, S. K., Deshpande, R. H., Madole, M. B. and Pathan, F. J. 2013. Assessment of III MBBS Students using OSCE in Community Medicine: Teachers' and students' Perceptions. Sch. J. App. Med. Sci., 2013; 1(4):348-353.

17. Wikipedia, 2010. Objective structured Clinical Examination en.wikipedia.org/wiki/ Objective Structured Clinical Examination. Retrieved $11^{\text {th }}$ November, 2014 